\title{
An Interventional Follow up Study to Determine the Effect of Nepafenac $0.1 \%$ in Macular thickness in Patients who had Undergone Cataract Surgery as Determined By OCT
}

\section{Rama Vadapalli *1, Vankadara Naga Suresh ?.}

${ }^{* 1}$ Assistant professor, Department of Ophthalmology, Santhiram M edical College, Nandyal, Andhra Pradesh, India.

${ }^{2}$ Associate professor, Department of Ophthalmology, Viswa Bharathi Medical College, Kurnool, Andhra Pradesh, India.

\section{ABSTRACT}

Background: Pseudophakic cystoid macular edema (CME) also known as Irvine-Gass syndrome, is one of the most common causes of visual loss after cataract surgery. Pathogenesis is thought to involve the release of inflammatory mediators, and non steroidal anti-inflammatory medications are often used for CM E prophylaxis. The aim of the study is to determine the role of Nepafenac $0.1 \%$ usage in altering the status of CM Eas determined by OCT who underwent Cataract Surgery.

Materials and M ethods: A total of 100 subjects with a 1:1 control: Treatment ratio that underwent small incision cataract surgery (SICS), Subjects were randomised in to 50 control group (standard of care only) and 50 treatment group (Standard of care plus nepafenac). Immediate post operatively, OCT scans were carried out on 1st post-operative day and at 4 weeks, using the macular thickness protocol with the stratus OCT version 5.0.1 at Santhiram General Hospital, Nandyal, between 2012- 15.

Results: In present study, the results demonstrated that with usage of postoperative topical nepafenac $0.1 \%$ there were differences between the treatment group and control group regarding the OCT measured macular thickness. After analysing the data and applying appropriate statistical analysis it can be concluded that $0.1 \%$ Nepafenac can be used as a treatment option for primary CME in post cataract patients. Topical therapy of $0.1 \%$ Nepafenac related side effects like Keratitis, corneal melt \& corneal perforation are very rare and were not encountered in any patient in our study.

Conclusion: In our study, results concluding that the topical nepafenac $0.1 \%$ therapy has promising results for prevention of pseudophakic cystoid macular edema.

KEY WORDS: cystoid macular edema, OCT, macular thickness, Nepafenac $0.1 \%$.

Address for correspondence: Dr. Rama Vadapalli. Assistant professor, Department of Ophthalmology, Santhiram M edical College, Nandyal, Andhra Pradesh, India.

E-Mail: ramav1728@gmail.com

\begin{tabular}{|c|c|c|}
\hline \multicolumn{3}{|c|}{ Online Access and Article Informtaion } \\
\hline \multirow{2}{*}{$\begin{array}{c}\text { Quick Response code } \\
\text { Dol: } 10.16965 / \text { ijims.2016.150 }\end{array}$} & \multicolumn{2}{|c|}{$\begin{array}{l}\text { International Journal of Integrative Medical Sciences } \\
\text { www.imedsciences.com }\end{array}$} \\
\hline & $\begin{array}{l}\text { Received: 16-09-2016 } \\
\text { Reviewed: 16-09-2016 }\end{array}$ & $\begin{array}{l}\text { Accepted: 26-09-2016 } \\
\text { Published: 31-10-2016 }\end{array}$ \\
\hline Source of Funding: Self & \multicolumn{2}{|c|}{ Conflicts of interest: None } \\
\hline
\end{tabular}

\section{BACKGROUND}

Pseudophakic cystoid macular edema (CME) also known as Irvine-Gass syndrome, is one of the most common causes of visual loss after cataract surgery. Pathogenesis is thought to involve the release of inflammatory mediators, and non steroidal anti-inflammatory medications are often used for CME prophylaxis. FDA approved NSAID'S for postoperative inflammation: Ketorolac 0.4\% ,Diclofenac 0.1\%, Bromfenac $0.09 \%$, Nepafenac $0.1 \%$. Of note, nepafenac is the newest of the above medica- 
tions, and has gained popularity.

Our study chooses nepafenac, because it is a prodrug that may be more efficacious and safer than nonprodrug NSAIDs. $0.1 \%$ nepafenac is a new ophthalmic NSAID and is the only one with a prodrug structure, making it a neutral molecule. This property, unlike the acidic nature of the other topical NSAIDs, allows nepafenac to rapidly penetrate the cornea, after which it is converted by intraocular hydrolases to its more active moiety amfenac (Ke et al 2000)[1).

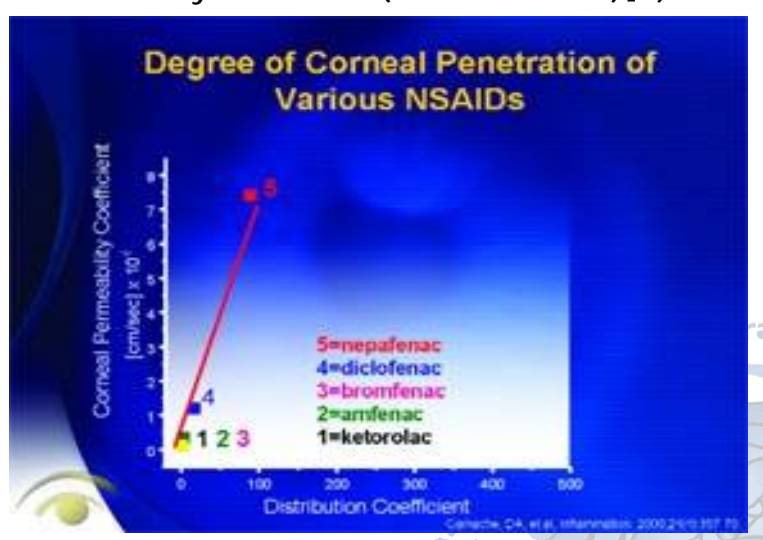

Conventional NSAIDs typically penetrate the intraocular tissues at a much slower rate than nepafenac, thus providing reduced efficacy in the retina and choroid, the target sites for $\mathrm{CME}$ prevention.

Nepafenac is unique, in that its bioconversion to amfenac is targeted to the irisciliary body and, to an even greater extent, the retina/choroid, suggesting nepafenac may have prolonged activity in the vascularized tissues of the eye (Ke et al 2000) [1].

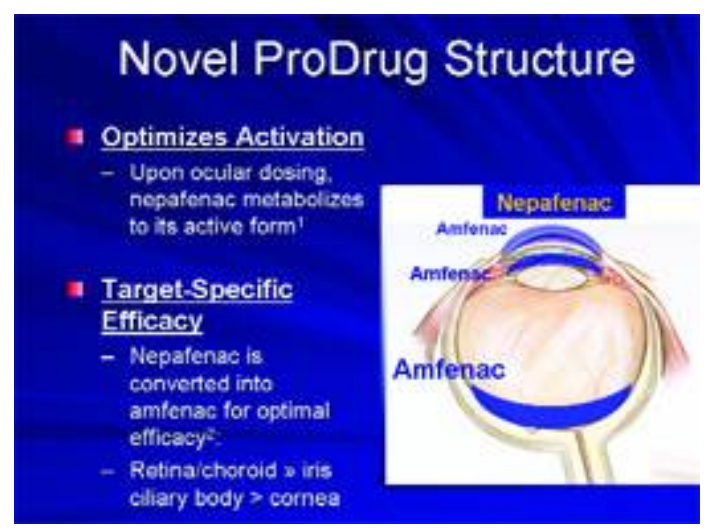

In support of this hypothesis, a rabbit model of paracentesis-induced ocular inflammation demonstrated that nepafenac exhibited a more complete and longer lasting inhibition of iris/ ciliary body prostaglandin synthesis than diclofenac (Gamache et al 2000)[2].
According to Lindstrom et al.[3], nepafenac's ability to inhibit prostaglandin synthesis plays a role in suppressing inflammation and cystoid macula edema following cataract surgery.

Taken together, this preclinical evidence suggests that nepafenac would compare favorably to conventional NSAIDs in the prevention and treatment of ocular inflammation associated with cataract surgery.

Macular thickness, as assessed by OCT in patients without Pseudophakic CME, peaks at approximately 4 to 6 weeks postoperatively $[4,5,6]$. Thus, it is not likely that many cases of Pseudophakic CME were missed in our studies.

Our study has relied on OCT for estimating changes in macular thickness. The conventional methods are able to detect approximately $80 \%$ of local areas of retinal thickening but are relatively insensitive to small changes in thickness or diffuse areas of thickening [7]. Since the accumulation of fluid can be due to the breakdown of the blood-retinal barrier, fluorescein angiography is routinely performed to detect areas of leakage. However, evidence exists that the amount of leakage does not correlate with the degree of thickening [8]. In response, several instruments have been developed to quantitatively assess macular thickness. Optical coherence tomography has emerged as a useful tool for quantitatively measuring foveal thickness in a reliable and reproducible manner [9,10-14].

Currently, in the literature OCT was found to be in good agreement with the clinical gold standard (slit lamp examination through a dilated pupil with a Non contact lens for detecting the presence or absence of macular edema and was found to be potentially more sensitive in cases of mild foveal thickening [15].

Nepafenac $0.1 \%$ is the newest topical NSAID available for the treatment of ocular pain and inflammation associate with cataract surgery. It has unique properties, including rapid corneal permeability and targeted intraocular activation due to its prodrug structure.

The aim of the study is to determine the role of Nepafenac $0.1 \%$ usage in altering the status of CME as determined by OCT who underwent Cataract Surgery. 


\section{MATERIALS AND METHODS}

A total of 100 subjects with a 1:1 control: Treatment ratio that underwent small incision cataract surgery (SICS), Subjects were randomised in to 50 control group (standard of care only) and 50 treatment group (Standard of care plus nepafenac). Immediate post operatively, OCT scans carried out on 1st postoperative day and at 4 weeks, using the macular thickness protocol with the stratus OCT version 5.0.1 at Santhiram General Hospital, Nandyal, between 2012- 15.

Inclusion Criteria: Patients who underwent cataract surgery without any systemic disease.

Exclusion criteria: 1 . Conditions that could increase risk of post cataract CM E like

a. Hypertension. b. Diabetes c. IHD d. History of uveitis. e. Use of topical prostaglandinanalogues for glaucoma.

2. Cases with other macular diseases accounting for macular thickness such as:

a. Retinal vascular diseases, b. Macular degenerations. Opacities of media affecting vision - Corneal, lenticular, vitreous opacities (as the OCT images will be lesser quality.

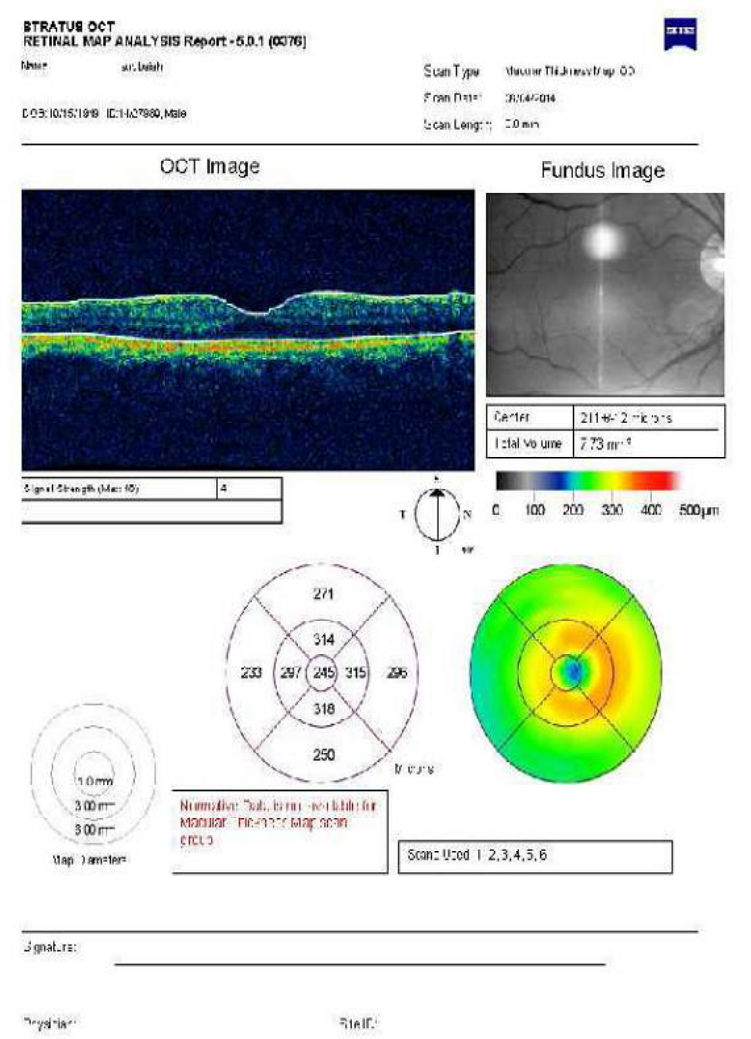

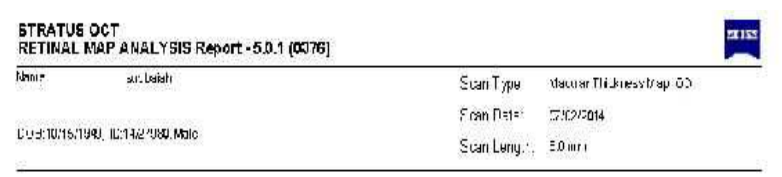

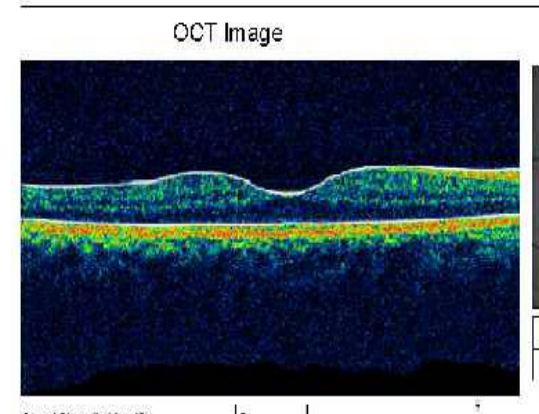

Fundus Image
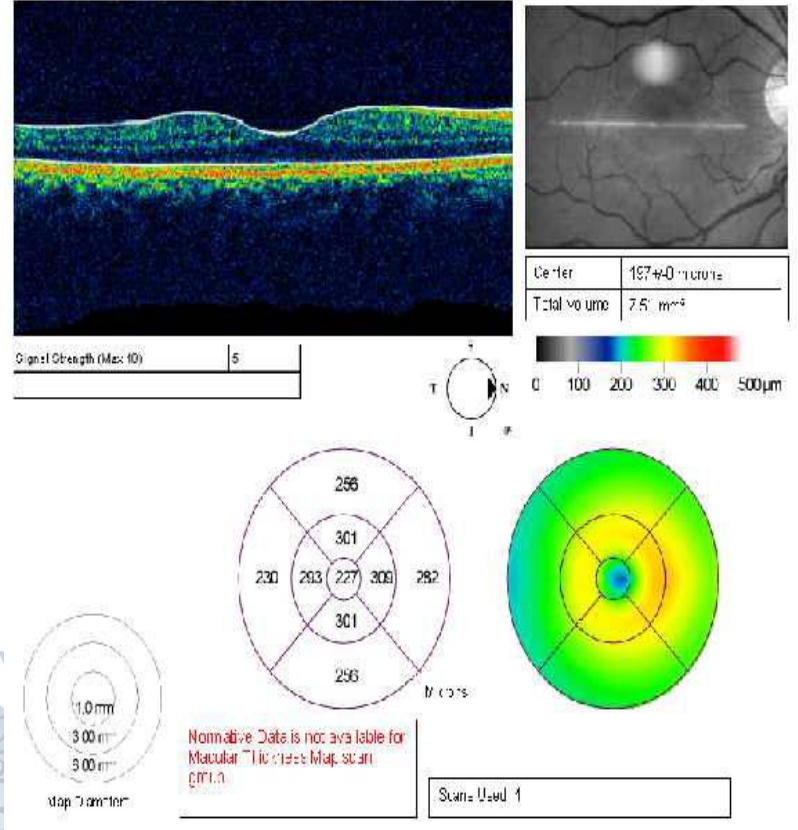

\section{.}

\section{.}
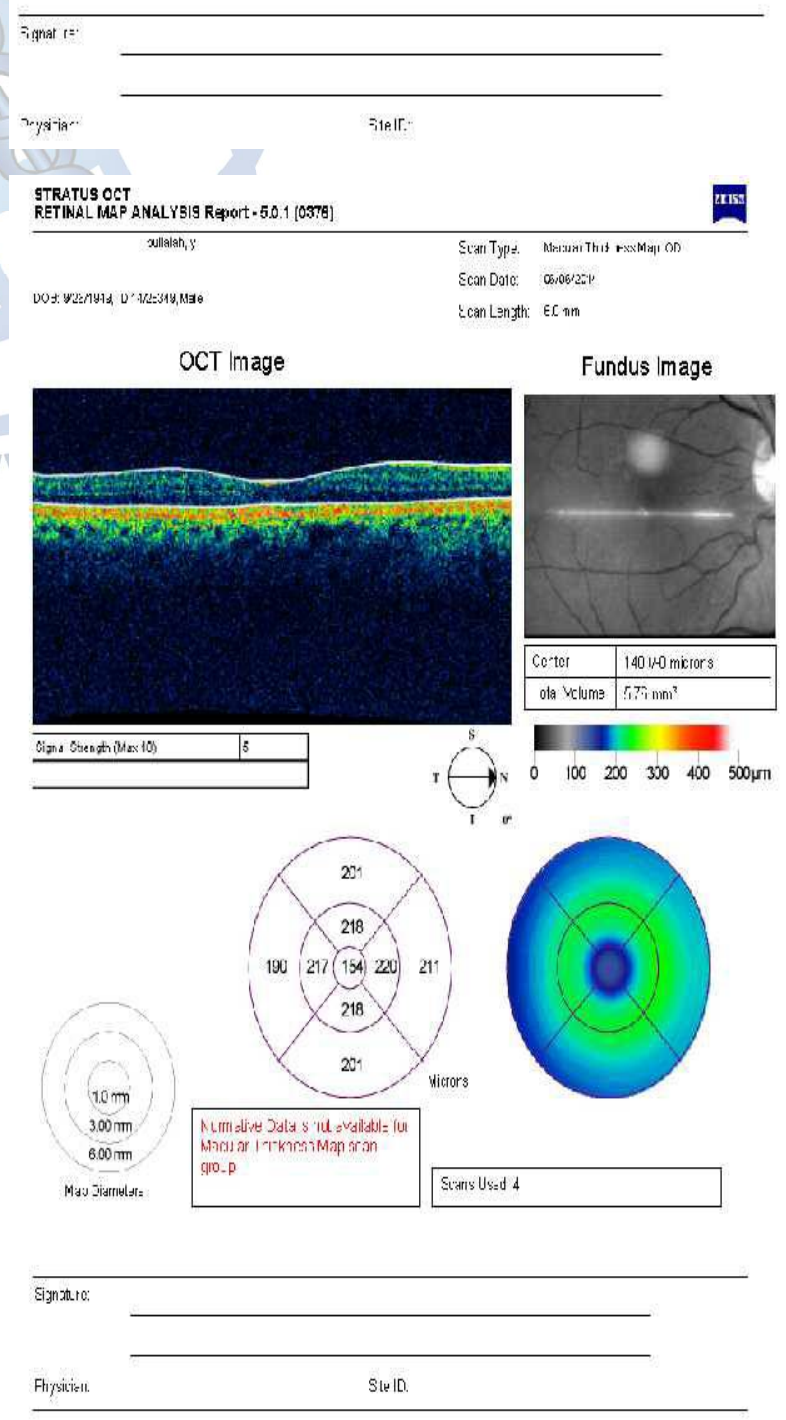


\section{RESULTS}

Table 1: Comparison Of Impact Of $0.1 \%$ Nepafenac On Macular Thickness After Cataract Surgery.

\begin{tabular}{|c|c|c|c|c|c|c|}
\hline \multirow{2}{*}{$\begin{array}{l}\text { Usage of } \\
\text { Nefenac }\end{array}$} & \multicolumn{2}{|c|}{$\begin{array}{l}1^{\text {st }} \text { post op day macular } \\
\text { thickness }\end{array}$} & \multicolumn{2}{|c|}{$\begin{array}{l}4 \text { weeks post op } \\
\text { macular thickness }\end{array}$} & \multirow[t]{2}{*}{ tvalue } & \multirow[t]{2}{*}{ Pvalue } \\
\hline & Mean & SD & Mean & SD & & \\
\hline Yes & 196.12 & 19.1563 & 183.1 & 15.1755 & 3.76715 & $\begin{array}{c}0.00028 \\
\text { Sig. }\end{array}$ \\
\hline No & 184.02 & 12.5722 & 198.24 & 18.1654 & 4.5515 & $\begin{array}{c}0.00001 \\
\text { Sig. }\end{array}$ \\
\hline t value & \multicolumn{2}{|c|}{3.734 sig. } & \multicolumn{2}{|c|}{4.52281} & & \\
\hline Pvalue & \multicolumn{2}{|c|}{0.0003 Sig. } & \multicolumn{2}{|c|}{0.00001} & & \\
\hline
\end{tabular}

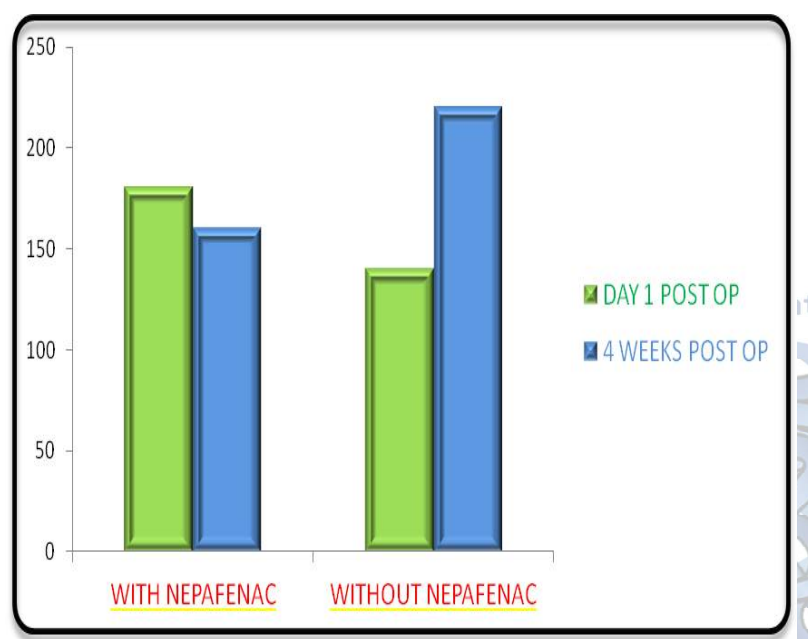

\section{DISCUSSION}

This interventional prospective, clinical study demonstrated that, based on retinal thickening treatment with nepafenac beginning post surgically was associated with a reduction in risk of macular edema and associated loss of visual acuity in patients. OCT measured macular thickness after cataract surgery is well documented. The statistical method which was used was student ' $t$ ' test with version SPSS 22.0. The basic statistics followed were mean and standard deviation. This ' $t$ ' test can be used to determine if two sets of data are significantly different from each other When post operative 1day and 4 weeks OCT measurements were compared. In this study the mean macular thickness were on 1st post-operative day is $196.12 \pm 19.1563 \mathrm{im}$ and at 4 weeks it is $183.01+15.1755 \mathrm{im}$ in the treatment group with nepafenac. In the control group it were $184.02 \pm 12.5722 \mathrm{im}$ on 1st postoperative day and $198.24 \pm 18.1654 \mathrm{im}$ at 4 weeks. That means there is increased macular thickness at 4weeks in the control group which was statistically significant where in $p$ value being 0.001 .
Enumerating the number of patients who evidenced with cystoid macular edema, at 4 weeks, it was nill in case of treatment group.

In our study, results demonstrated that topical $0.1 \%$ therapy has promising results for prevention of pseudophakic cystoid macular edema.

Substantial visual improvement in the postsurgical period was reported by $M$ iyake et al in a study.

Miyake et al. [16] designed a double masked, randomized, interventional study in 59 patients comparing topical $0.1 \%$ nepafenac to $0.1 \%$ fluorometholone (FM L) in preventing $\mathrm{CME}$ and blood-aqueous barrier (BAB) disruption up to 5 weeks after small incision cataract surgery. The purpose of the study was to quantify these medications' impact on CME and BAB function using fluorescein angiography (FA), retinal foveal thickness as measured by OCT, and laser flarecell photometry, as well as their effect on postop visual outcome and safety profiles. Analysis demonstrated angiographic CME was present in $14.3 \%$ (grade III by Miyake classification in $0.0 \%$ ) and $81.5 \%$ (grade III in $18.5 \%$ ) in the nepafenac and FM L groups, respectively, which was a statistically significant difference.

There was a significant increase in foveal thickness on OCT in the FM L group compared to the nepafenac group at 2 and 5 weeks post-op. There was significantly less flare in the nepafenac group compared to the FM L group. In this study, fewer patients in the nepafenac group developed macular edema relative to patients in the control group, with significant differences seen as early as after cataract surgery, which persisted for 1st week and 4th week after surgery. The results further showed that patients in the nepafenac group, when compared with those in the control group, maintained better visual acuity, with fewer decreases over the course of the study. In addition to preventing macular edema and the Associated loss of visual acuity, increases in macular thickening and volume were also observed to be less severe in patients who received nepafenac than in controls.

These results are consistent with previous 
clinical studies and further support the conclusion that nepafenac effectively reduced the incidence and severity of macular edema. In a retrospective study based upon chart reviews of 450 patients, although visually significant pseudophakic macular edema occurred in patients treated for 4 weeks following cataract surgery either with a combination of nepafenac and prednisolone or with prednisolone alone, the percentage of patients who developed macular edema was significantly lower in the combination therapy group than in the monotherapy group (0\% and $2 \%$, respectively; $P$ $=0.035) 7$. Additionally, two published case series have reported reduction in macular thickness and improvement in visual acuity following treatment with nepafenac in patients with diabetic macular edema secondary to either cataract surgery or various retinal diseases [17-19].

Similar to our stud y Rishi Singh et al. [20] found in their study, the beneficial effect of nepafenac in preventing macular edema and associated loss of visual acuity was also supported by the decreased extent of mean macular thickening and volume observed at all postoperative study visits in the nepafenac group relative to the vehicle group. Hariprasad SM et al [21], Multicenter retrospective. Review of $22 \mathrm{CME}$ cases (20 patients) treated with nepafenac $0.1 \%$ (six with concomitant prednisolone acetate $1 \%$ ) conducted from December 2005 to April 2008. Following treatment for six weeks to six months, six eyes with uveitic $\mathrm{CM}$ E showed a mean retinal thickness improvement of $227+/-168.1 \mathrm{im}$; mean best-corrected visual acuity (BCVA) improvement was $0.36+/-0.20 \log M A R$. All three cases of acute pseudophakic CME improved after four to 10 weeks of nepafenac, with a mean improvement in retinal thickness of $134 \mathrm{t}$ - $111.0 \mathrm{im}$. BCVA improved in two patients ( 0.16 and $0.22 \log M A R$ ) but not in the third due to underlying retinal pigment epithelium changes. Thirteen eyes with chronic/ recalcitrant pseudophakic CM E demonstrated a mean improvement in retinal thickness of 178 +/-128.7im after nepafenac and mean CVA improvement of $0.33+/-0.19 \log M A R$. They also concluded that the positive outcomes of these 22 eyes strongly suggest that nepafenac $0.1 \%$ is a promising drug. Enumerating the number of patients who evidenced with cystoid macular edema, at 4 weeks, it was nill in case of treatment group. In our study, results demonstrated that topical $0.1 \%$ therapy has promising results for prevention of pseudophakic cystoid macular edema. Similar to my findings Dr.Rama $V$ An interventional follow up study to determine the effect of nepafenac $0.1 \%$ in macular thickness in patients who had undergone cataract Surgery as determined by oct. 50 control and 50 treatment group. Nepafenac is effective in preventing postoperative cystoid macular oedema. The drawbacks of the study were not considering BCVA, short follow up periods. Macular thickness, as assessed by OCT in patients without Pseudophakic CME, peaks at approximately 4 to 6 weeks postoperatively. Thus, it is not likely that many cases of Pseudophakic CM E were missed in our studies.

\section{CONCLUSION}

In present study, the results demonstrated that with usage of postoperative topical nepafenac $0.1 \%$ there were differences between the treatment group and control group regarding the OCT measured macular thickness. After analysing the data and applying appropriate statistical analysis it can be concluded that $0.1 \%$ Nepafenac can be used as a treatment option for primary CME in post cataract patients. Topical therapy of $0.1 \%$ Nepafenac related side effects like Keratitis, corneal melt $\&$ corneal perforation are very rare and were not encountered in any patient in our study. The drawbacks of the study were not considering BCVA, short follow up periods. M acular thickness, as assessed by OCT in patients without Pseudophakic CM E, peaks at approximately 4 to 6 weeks postoperatively. Thus, it is not likely that many cases of Pseudophakic CME were missed in our studies.

\section{REFERENCES}

[1]. Ke TL, Graff G, Spellman JM, et al. Nepafenac, a unique nonsteroidal pro-drug with potential utility in the treatment of trauma-induced ocular inflammation: II. In vitro bioactivation and permeation of external ocular barriers. Inflammation. 2000;24:371-84

[2]. Gamache DA, Graff G, Brady MT, et al. Nepafenac, a unique nonsteroidal prodrug with potential utility in the treatment of trauma-induced ocular inflam- 
-mation. I Assessment of anti-inflammatory efficacy. Inflammation. 2000;24:357-70.

[3]. Lindstrom R, Kim T (2006) Ocular permeation and inhibition of retinal inflammation: an examination of data and expert opinion on the clinical utility of Nepafenac. Curr Med Res Opin 22: 397-404.

[4]. Perente I, Utine CA, Ozturker C, et al. Evaluation of macular changes after uncomplicated phacoemulsification surgery by optical coherence tomography. Curr Eye Res 2007;32: 241-7.

[5]. Nicholas S, Riley A, Patel H, et al. Correlations between optical coherence tomography measurement of macular thickness and visual acuity after cataract extraction. Clin Experiment Ophthalmol 2006;34:124-9.

[6]. Ching HY, Wong AC, Wong CC, et al. Cystoid macular oedema and changes in retinal thickness after phacoemulsification with optical coherence tomography. Eye (Lond) 2006;20:297-303.

[7]. Shahidi M, Ogura Y, Blair NP, et al. Retinal thickness analysis for quantitative assessment of diabetic macular edema. Arch Ophthalmol. 1991;109:11151119.

[8]. Nussenblatt RB, Kaufman SC, Palestine AG, et al. Macular thickening and visual acuity. Ophthalmology. 1987;94:1134-1139.

[9]. Hee MR, Puliafito CA, Wong C, et al. Quantitative assessment of macular edema with optical coherence tomography. Arch Ophthalmol. 1995;113:1019-1029.

[10]. Hee M R, Puliafito CA, Duker JS, et al. Topography of diabetic macular edema with optical coherence tomography. Ophthalmology. 1998;105:360-370.

[11]. Konno S, Akiba J, Yoshida A. Retinal thickness measurements with optical co-

[12]. Neubauer AS, Priglinger S, Ullrich S, et al. Comparison of foveal thickness measured with the retinal thickness analyzer and optical coherence tomography. Retina. 2001;21:596-601.
[13].Massin P, Vicaut E, Haouchine B, et al. Reproducibility of retinal mapping using optical coherence tomography. Arch Ophthalmol. 2001;119:1135-1142.

[14]. Jaffe GJ, Caprioli J. Optical coherence tomography to detect and manage retinal disease and glaucoma. Am J Ophthalmol. 2004;137:156-169.

[15]. Brown JC, Solomon SD, Bressler SB, et al. Detection of diabetic foveal edema: contact lens biomicroscopy compared with optical coherence tomography. Arch Ophthalmol. 2004;122:330-335

[16]. Miyake K, Ibaraki N. Prostaglandins and cystoids macular edema. Surv Ophthalmol 2002; 47(suppl 1):S203-S218.

[17]. Hariprasad SM, Akduman L, Clever JA, Ober M, Recchia FM, Mieler WF. Treatment of cystoids macular edema with the new-generation NSAID nepafenac $0.1 \%$. Clin Ophthalmol. 2009;3:147-154.

[18]. Hariprasad SM, Callanan D, Gainey S, He YG, Warren K. Cystoid and diabetic macular edema treated with nepafenac $0.1 \%$. J Ocul Pharmacol Ther.2007;23:585-590.

[19]. Callanan D, Williams P. Topical nepafenac in the treatment of diabetic macular edema. Clin Ophthalmol. 2008;2:689-692.

[20]. Rishi Singh, Louis Alpern, Glenn J Jaffe, Robert $P$ Lehmann, John Lim, HarveyJ Reiser, et al. Evaluation of nepafenac in prevention of macular edema following cataract surgery in patients with diabetic retinopathy. Clinical Ophthalmology 2012;6:125969.

[21].Hariprasad SM, Akduman L, Clever JA, Ober M, Recchia FM, Mieler WF. Treatment of cystoids macular edema with the new-generation NSAID nepafenac $0.1 \%$. Clin Ophthalmol. 2009;3:147-154.

\footnotetext{
How to cite this article:

Rama Vadapalli, Vankadara Naga Suresh. An Interventional Follow up Study to Determine the Effect of Nepafenac $0.1 \%$ in M acular thickness in Patients who had Undergone Cataract Surgery as Determined By OCT. Int J Intg M ed Sci 2016;3(10):427-432. DOI: 10.16965/ijims.2016.150
} 